Supporting Information

\title{
Processing-Dependent Lamellar Polymorphism of Hyperbranched Liquid-Crystalline Polymer with Variable Light Emission
}

\author{
Bin $\mathrm{Mu}$, Xun Li, Yu Zhao, Xuhong Quan, Wei Tian* \\ Shanxi Key Laboratory of Macromolecular Science and Technology, MOE Key Laboratory of Material \\ Physics and Chemistry under Extraordinary Conditions, School of Chemistry and Chemical \\ Engineering, Northwestern Polytechnical University, Xi'an, 710072, China. \\ *E-mail: happytw_3000@nwpu.edu.cn
}

\section{Table of Contents}

1. Materials and Measurements

2. Preparation of the HLCP

3. Thermal Analysis

4. Spectroscopic Properties

5. Structural Characterization

6. Synthesis and Characterization of the Linear LC Polymer Analogue 


\section{Materials and Measurements}

Materials. Glutamic acid (>92\%, TCI), 10-bromo-1-decanol (96\%, Innochem), 4ethynylbenzaldehyde (98\%, Innochem), methyl 4-(cyanomethyl)benzoate ( $>98 \%$, Innochem), and $N$ (tert-butoxycarbonyl)- $\beta$-alanine (98\%, Innochem) were used as received. All other chemical reagents were commercially available and used as received.

Measurements. ${ }^{1} \mathrm{H}$ NMR and ${ }^{13} \mathrm{C}$ NMR spectra in solution were obtained from Bruker Avance 400 instruments. Multiplicities are denoted as follows: $\mathrm{s}=$ singlet, $\mathrm{d}=$ doublet, $\mathrm{t}=$ triplet, and $\mathrm{m}=$ multiplet. Fourier transform infrared spectra (FTIR) were recorded on a Bruker Vertex70 microinfrared spectrometer. Mass spectra was recorded on a LCMS-2020 single quadrupole equipped with an electrospray ionization (ESI) source interface (Shimadzu). Matrix-assisted laser desorption/ionization time-of-flight mass spectrometry (MALDI-TOF-MS) was performed on a Bruker Autoflex II instrument, with $\alpha$-Cyano-4-hydroxycinnamic acid (CHCA) employed as the matrix substance. Gel-permeation chromatography (GPC) measurements were performed at $25{ }^{\circ} \mathrm{C}$ on a Waters 515 equipped with a Wyatt Technology Optilab rEX differential refractive index detector by using tetrahydrofuran as an eluent at a flow rate of $1.0 \mathrm{~mL} / \mathrm{min}$. Relative weight average $\left(M_{\mathrm{w}}\right)$ and number average $\left(M_{\mathrm{n}}\right)$ molecular weights were calculated with a calibration curve based on a group of polystyrene standard samples. Inductively Coupled Plasma-Mass Spectrometry (ICP-MS) was performed on an Agilent 7700 instrument. Polarized optical microscopy (POM) was adopted to characterize thermal transitions, observe and photograph textures with a Nikon E400POL microscope equipped with an Instec HCS302 hot and cold stage. Thermal gravimetric analysis (TGA) was carried out on a Netzsch simultaneous thermal analysis instrument under argon atmosphere at a flow rate of $40 \mathrm{~mL} \mathrm{~min}-1$ with the scanning rate of $20{ }^{\circ} \mathrm{C} \min ^{-1}$ from $35{ }^{\circ} \mathrm{C}$ to $600{ }^{\circ} \mathrm{C}$. Differential scanning calorimetry (DSC) thermograms were recorded on a Mettler Toledo DSC 1 system equipped with a cooling accessory and under nitrogen atmosphere at a flow rate of $20 \mathrm{~mL} \mathrm{~min}^{-1}$. Typically, about $6 \mathrm{mg}$ of the solid sample was encapsulated in a sealed aluminum pan with an identical empty pan as the reference with a heating or cooling rate of $10{ }^{\circ} \mathrm{C} \mathrm{min}^{-1}$. X-ray scattering experiments were performed with Anton Paar SAXSpoint 2.0 small-angle X-ray scattering instruments. The scattering vector $q$ is defined as $4 \pi \sin \theta / \lambda$, where the wavelength $\lambda$ is $0.1542 \mathrm{~nm}$ of $\mathrm{Cu}-\mathrm{K}_{\alpha}$ radiation and $2 \theta$ is the scattering angle. X-ray diffraction experiment was conducted on a Bruker D8 advance X-ray diffracmeter with 
$\mathrm{Cu}-\mathrm{K}_{\alpha}$ as the radiation. Ultraviolet visible (UV-vis) absorption spectra were recorded on a Shimadzu UV-2550 spectrometer. Fluorescence spectra and time-resolved fluorescence lifetime experiments were recorded with an Edinburgh FLS1000 transient steady-state fluorescence spectrometer, where the time-resolved lifetime was obtained by adopting a $340 \mathrm{~nm}$ picosecond pulsed excitation source.

\section{Preparation of the HLCP}
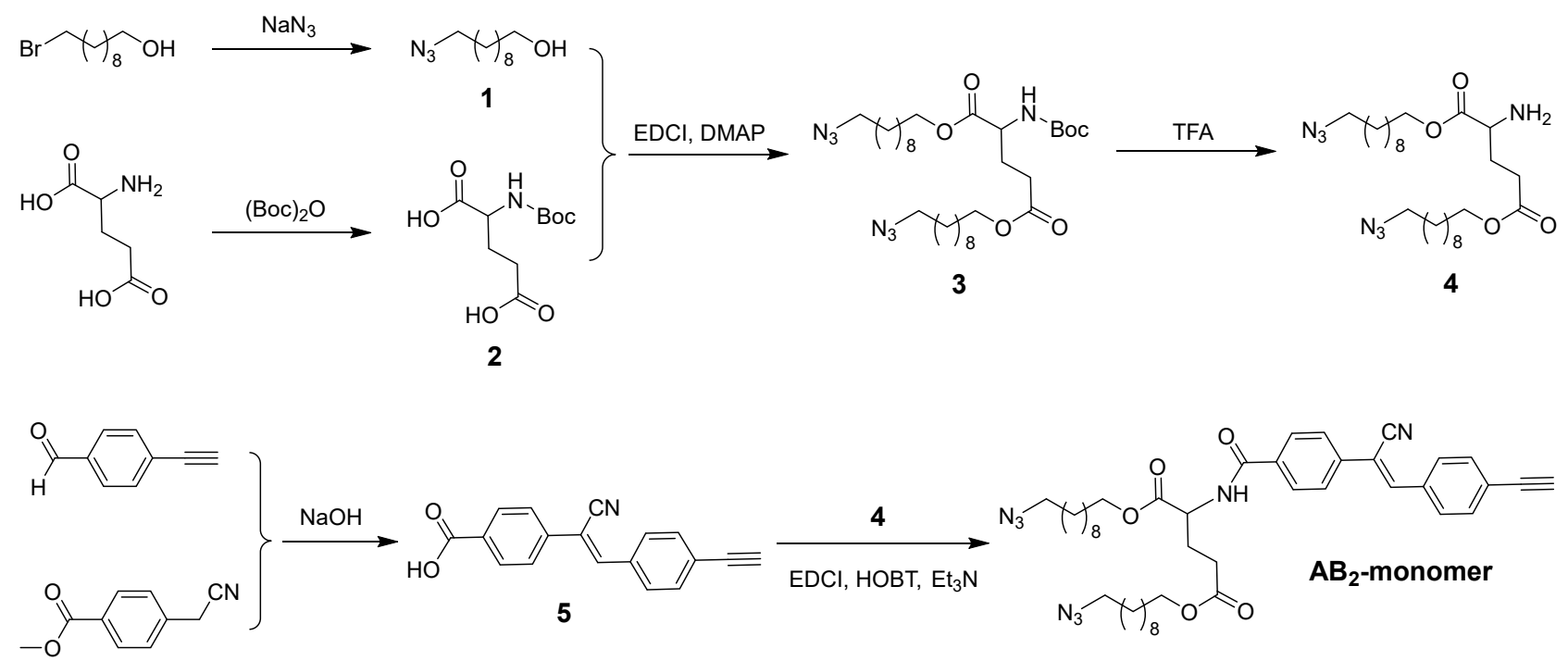

Scheme S1. Synthetic route of the $\mathrm{AB}_{2}$-monomer.

10-Azido-1-decanol (1). A mixture of 10-bromo-1-decanol $(2.1 \mathrm{~g}, 8.86 \mathrm{mmol})$ and sodium azide $\left(\mathrm{NaN}_{3}, 1.2 \mathrm{~g}, 18.5 \mathrm{mmol}\right)$ in $35 \mathrm{~mL} N, N$-dimethylformamide (DMF) was stirred at $50{ }^{\circ} \mathrm{C}$ for $36 \mathrm{~h}$. After cooling to room temperature, the reaction mixture was poured into $100 \mathrm{~mL}$ water and then extracted with ethyl acetate to give a desired product $(1.6 \mathrm{~g})$ in light yellow oil. Yield $91 \%$. ${ }^{1} \mathrm{H}$ NMR $\left(400 \mathrm{MHz}, \mathrm{CDCl}_{3}\right): \delta(\mathrm{ppm})=3.63(\mathrm{t}, 2 \mathrm{H}, J=6.4 \mathrm{~Hz}), 3.25(\mathrm{t}, 2 \mathrm{H}, J=6.8 \mathrm{~Hz}), 1.64-1.52(\mathrm{~m}, 4 \mathrm{H})$, $1.41-1.26(\mathrm{~m}, 12 \mathrm{H})$.

(tert-Butoxycarbonyl) glutamic acid (2). A mixture of glutamic acid (2.7 g, $18.4 \mathrm{mmol})$ and triethylamine $\left(\mathrm{Et}_{3} \mathrm{~N}, 5 \mathrm{~mL}\right)$ in a mixed solvent of $24 \mathrm{~mL} \mathrm{DMF}$ and $16 \mathrm{~mL}$ water was stirred for $10 \mathrm{~min}$, resulting in a clear solution. Di-tert-butyl dicarbonate $\left((\mathrm{Boc})_{2} \mathrm{O}, 4.5 \mathrm{~g}, 20.6 \mathrm{mmol}\right)$ was added slowly to the solution that was stirred for $1 \mathrm{~h}$. After removal of the solvent, $100 \mathrm{~mL}$ ethyl acetate was added to dissolve the residue, which was washed with $1 \mathrm{M} \mathrm{HCl}$ aqueous solution, saturated $\mathrm{NaCl}$ solution, and 
then dried by anhydrous $\mathrm{Na}_{2} \mathrm{SO}_{4}$. Finally, after filtration of the solution, the solvent was removed to give a desired product $(1.6 \mathrm{~g})$ in light yellow oil. Yield 91\%. ${ }^{1} \mathrm{H}$ NMR $\left(400 \mathrm{MHz}, \mathrm{CDCl}_{3}\right): \delta(\mathrm{ppm})=$ $5.33(\mathrm{~d}, 1 \mathrm{H}, J=7.2 \mathrm{~Hz}), 4.48-4.32(\mathrm{~m}, 1 \mathrm{H}), 2.51(\mathrm{t}, 2 \mathrm{H}, J=6.8 \mathrm{~Hz}), 2.16(\mathrm{~m}, 2 \mathrm{H}) 1.45(\mathrm{~s}, 9 \mathrm{H})$.

Bis(10-azidodecyl) (tert-butoxycarbonyl)glutamate (3). To a solution of 2 (2.0 g, 8.1 mmol), 1-(3dimethylaminopropyl)-3-ethylcarbodiimide hydrochloride (EDCI, $5.8 \mathrm{~g}, 30.2 \mathrm{mmol}$ ), and 4dimethylaminopyridine (DMAP, $0.62 \mathrm{~g}, 5.1 \mathrm{mmol}$ ) in $60 \mathrm{~mL}$ chloroform and $20 \mathrm{~mL}$ DMF, a solution of 1 (3.4 g, $17.1 \mathrm{mmol})$ in $15 \mathrm{~mL}$ dichloromethane was added under ice-water bath and then allowed to stir at $40{ }^{\circ} \mathrm{C}$ for $48 \mathrm{~h}$. The reaction mixture was cooled down to room temperature and was then poured into water. After extraction with dichloromethane, the crude product was purified by silica-gel column chromatography using mixed solvents of petroleum ether/ethyl acetate $(10: 1, \mathrm{v} / \mathrm{v})$ as the eluent to give a desired product (3.0 g) in light yellow viscous liquid. Yield 56\%. $\left.{ }^{1} \mathrm{H} \mathrm{NMR} \mathrm{(400} \mathrm{MHz,} \mathrm{CDCl}_{3}\right)$ : $\delta(\mathrm{ppm})=5.10(\mathrm{~d}, 1 \mathrm{H}, J=7.6 \mathrm{~Hz}), 4.31(\mathrm{~m}, 1 \mathrm{H}), 4.13(\mathrm{t}, 2 \mathrm{H}, J=6.8 \mathrm{~Hz}), 4.06(\mathrm{t}, 2 \mathrm{H}, J=6.8 \mathrm{~Hz})$, $3.26(\mathrm{t}, 4 \mathrm{H}, J=6.8 \mathrm{~Hz}), 2.48-2.31(\mathrm{~m}, 2 \mathrm{H}), 2.23-2.11(\mathrm{~m}, 2 \mathrm{H}), 1.69-1.52(\mathrm{~m}, 8 \mathrm{H}), 1.44(\mathrm{~s}, 9 \mathrm{H}), 1.41-$ $1.21(\mathrm{~m}, 24 \mathrm{H})$.

Bis(10-azidodecyl) glutamate (4). Trifluoroacetic acid (TFA, $32 \mathrm{~mL}$ ) was added to a solution of 3 (3.4 g, $5.6 \mathrm{mmol})$ in $50 \mathrm{~mL}$ dichloromethane under ice-water bath, that was allowed to stir for $4.5 \mathrm{~h}$. The reaction mixture was washed with saturated $\mathrm{NaHCO}_{3}$ solution for three times, and then the solvent was removed to give a desired product (2.8 g) in dark yellow viscous liquid. Yield 94\%. ${ }^{1} \mathrm{H}$ NMR (400 $\left.\mathrm{MHz}_{\mathrm{CDCl}}\right): \delta(\mathrm{ppm})=4.11(\mathrm{t}, 2 \mathrm{H}, J=6.7 \mathrm{~Hz}), 4.07(\mathrm{t}, 2 \mathrm{H}, J=6.7 \mathrm{~Hz}), 3.46(\mathrm{~m}, 1 \mathrm{H}), 3.26(\mathrm{t}, 4 \mathrm{H}$, $J=6.9 \mathrm{~Hz}), 2.46(\mathrm{t}, 2 \mathrm{H}, J=7.5 \mathrm{~Hz}), 2.14-2.02(\mathrm{~m}, 1 \mathrm{H}), 1.68-1.51(\mathrm{~m}, 8 \mathrm{H}), 1.41-1.21(\mathrm{~m}, 24 \mathrm{H})$.

(Z)-4-(1-cyano-2-(4-ethynylphenyl)vinyl)benzoic acid (5). To a solution of 4-ethynylbenzaldehyde $(0.5 \mathrm{~g}, 3.8 \mathrm{mmol})$ and methyl 4-(cyanomethyl)benzoate $(0.74 \mathrm{~g}, 4.2 \mathrm{mmol})$ in $80 \mathrm{~mL}$ ethanol at $80{ }^{\circ} \mathrm{C}$, potassium hydroxide $(0.86 \mathrm{~g}, 10 \mathrm{mmol})$ was added and then allowed to stir for $5 \mathrm{~h}$. After cooling down to room temperature, the reaction mixture was acidified by $4 \mathrm{~mL}$ concentrated $\mathrm{HCl}$ aqueous solution, resulting to a large number of precipitation formation. Finally, a simple filtration was used to give a desired product $(0.7 \mathrm{~g})$ in yellow solid. Yield 67\%. ${ }^{1} \mathrm{H}$ NMR (400 MHz, DMSO-d6): $\delta(\mathrm{ppm})=13.21$ $(\mathrm{s}, 1 \mathrm{H}), 8.23(\mathrm{~s}, 1 \mathrm{H}), 8.07(\mathrm{~d}, 2 \mathrm{H}, J=8.4 \mathrm{~Hz}), 7.99$ (d, 2H, $J=8.4 \mathrm{~Hz}), 7.92(\mathrm{~d}, 2 \mathrm{H}, J=8.4 \mathrm{~Hz}), 7.67$ $(\mathrm{d}, 2 \mathrm{H}, J=8.4 \mathrm{~Hz}), 4.46(\mathrm{~s}, 1 \mathrm{H})$. 
Bis(10-azidodecyl) (Z)-(4-(1-cyano-2-(4-ethynylphenyl)vinyl)benzoyl)glutamate ( $\mathrm{AB}_{2}$-monomer). To a solution of 4 (2.84 g, $5.6 \mathrm{mmol}), 5(1.44 \mathrm{~g}, 5.3 \mathrm{mmol})$ and 1-hydroxybenzotriazole (HOBT, 2.16 $\mathrm{g}, 16 \mathrm{mmol})$ in a mixed solvent of $80 \mathrm{~mL}$ dichloromethane and $25 \mathrm{~mL}$ tetrahydrofuran, EDCI (3.07 g, $16 \mathrm{mmol})$, and triethylamine $(1.83 \mathrm{~mL})$ were added under ice-water bath and then allowed to stir at room temperature for $20 \mathrm{~h}$. After washing with $1 \mathrm{M} \mathrm{HCl}$ aqueous solution, the solvent was removed to obtain the crude product, which was further purified by silica-gel column chromatography using mixed solvents of petroleum ether/dichloromethane/ethyl acetate $(8: 2: 1, \mathrm{v} / \mathrm{v} / \mathrm{v})$ as the eluent to give a desired product (2.3 g) in yellow solid. Yield 54\%. M.P. $63{ }^{\circ} \mathrm{C} .{ }^{1} \mathrm{H}$ NMR $\left(400 \mathrm{MHz}, \mathrm{CDCl}_{3}\right): \delta(\mathrm{ppm})=7.94$ $(\mathrm{d}, 2 \mathrm{H}, J=8.4 \mathrm{~Hz}), 7.91(\mathrm{~d}, 2 \mathrm{H}, J=8.4 \mathrm{~Hz}), 7.79(\mathrm{~d}, 2 \mathrm{H}, J=8.4 \mathrm{~Hz}), 7.62$ (d, 2H, $J=8.0 \mathrm{~Hz}), 7.61$ (s, 1H), 4.85-4.77 (m, 1H), $4.21(\mathrm{t}, 2 \mathrm{H}, J=6.8 \mathrm{~Hz}), 4.08(\mathrm{t}, 2 \mathrm{H}, J=6.8 \mathrm{~Hz}), 3.32-3.19(\mathrm{~m}, 4 \mathrm{H}), 2.62-$ $2.12(\mathrm{~m}, 5 \mathrm{H}), 1.76-1.53(\mathrm{~m}, 8 \mathrm{H}), 1.44-1.18(\mathrm{~m}, 24 \mathrm{H}) .{ }^{13} \mathrm{C}$ NMR $\left(100 \mathrm{MHz}, \mathrm{DMSO}-d_{6}\right): \delta(\mathrm{ppm})=$ $172.63,172.12$, 166.22, 143.42, 136.82, 134.60, 134.29, 132.69, 129.94, 128.79, 126.15, 124.49, $117.89,110.78,83.80,83.31,70.36,64.94,64.41,61.20,52.65,51.09,30.68,29.34,29.13,29.10$, 29.06, 29.02, 28.71, 28.57, 26.62, 26.18, 25.86, 25.82. MALDI-TOF-MS $(\mathrm{m} / \mathrm{z}):[\mathrm{M}+\mathrm{K}]^{+}$calcd 803.40, found 803.38 .
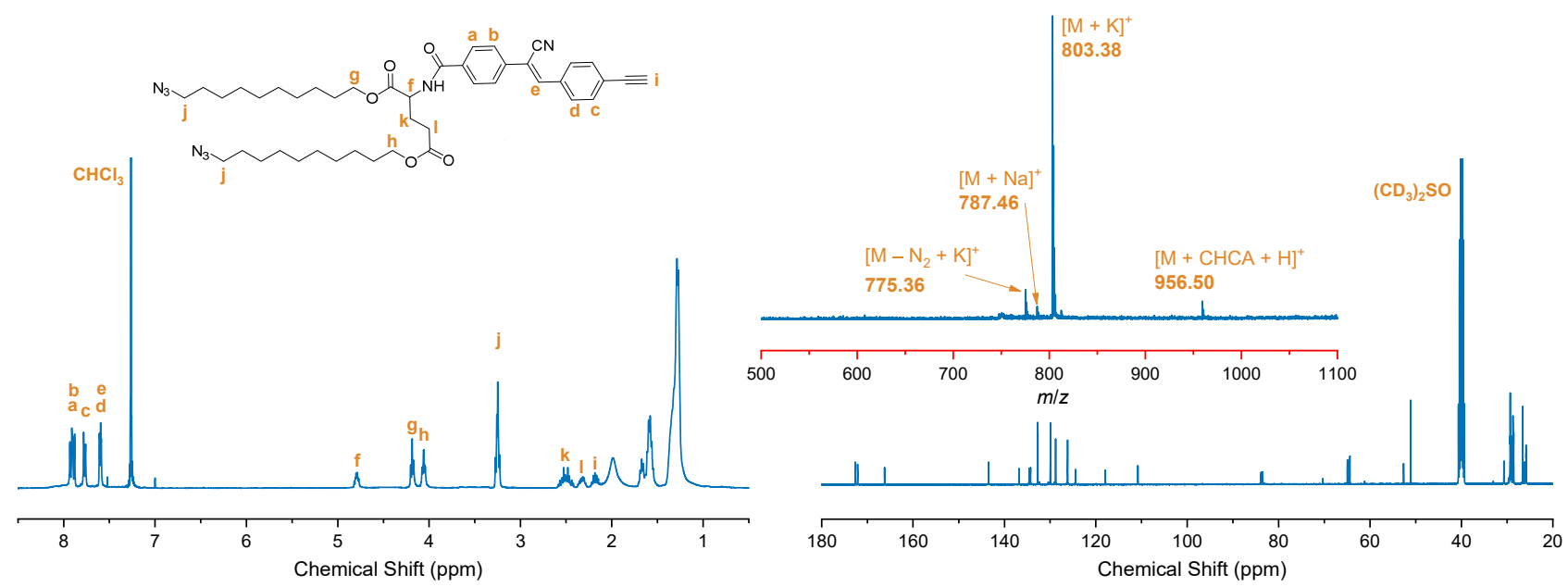

Figure S1. ${ }^{1} \mathrm{H}$ NMR, ${ }^{13} \mathrm{C}$ NMR, and MALDI-TOF-MS spectra of the $\mathrm{AB}_{2}$-monomer. 


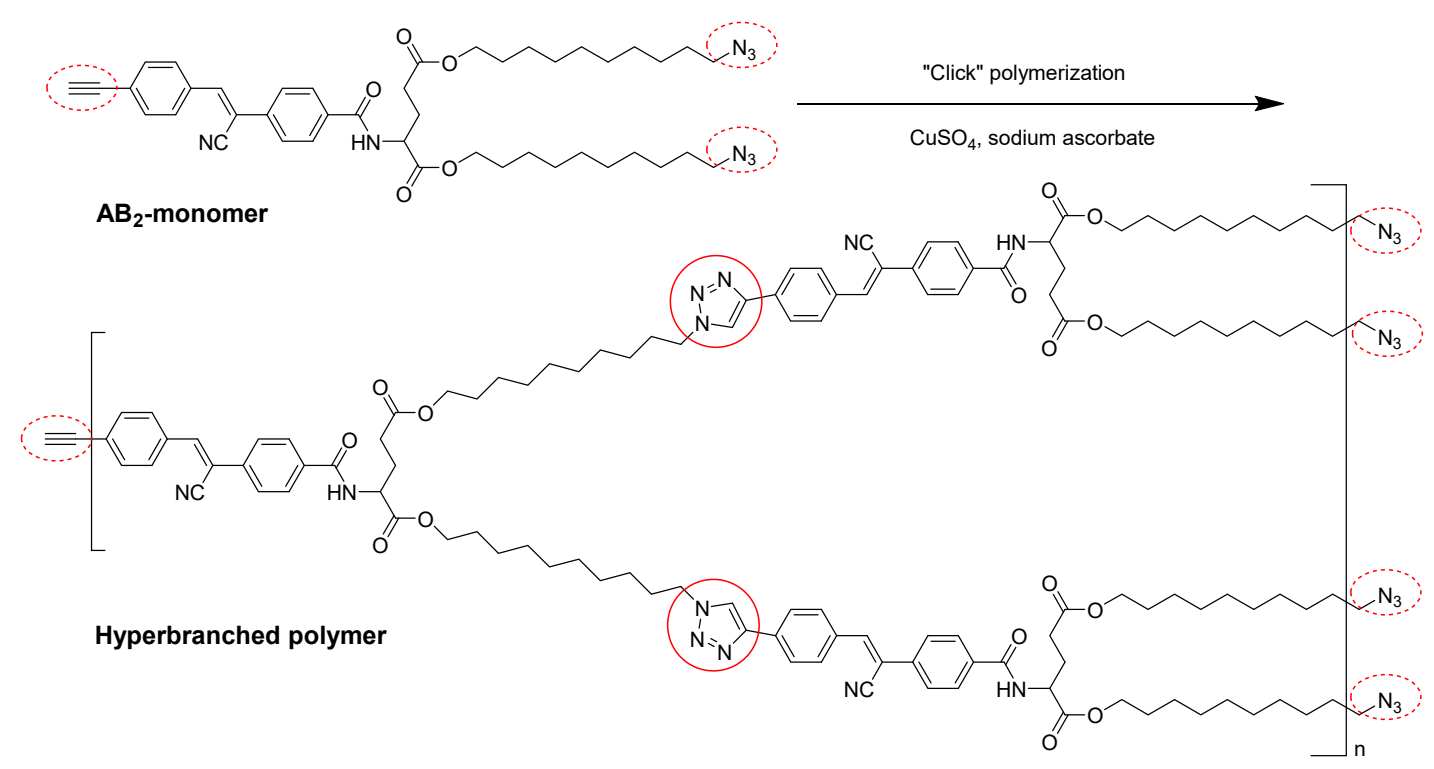

Scheme S2. Synthesis of the hyperbranched polymer from the $\mathrm{AB}_{2}$-monomer.

Hyperbranched polymer. The hyperbranched polymer was synthesized in an $\mathrm{AB}_{2}$-type azide-alkyne click polymerization, which was carried out in a $\mathrm{CuSO}_{4}$-sodium ascorbate system. $\mathrm{AB}_{2}$-monomer (100 $\mathrm{mg}, 0.12 \mathrm{mmol}$ ) was dissolved in $6 \mathrm{~mL} \mathrm{DMF}$ and degassed via freeze-pump-thaw cycle three times before filling with nitrogen. Then, $\mathrm{CuSO}_{4}$ aqueous solution $(0.15 \mathrm{~mL}, 0.006 \mathrm{mmol})$ and sodium ascorbate aqueous solution $(0.15 \mu \mathrm{L}, 0.012 \mathrm{mmol})$ was added to the solution that was stirred at room temperature for $24 \mathrm{~h}$. The reaction mixture was dropped into a large amount of methanol to remove the residual copper, monomer and possible oligomers, and the polymer precipitation was obtained by centrifugation. Yield 80\%. ICP-MS showed a copper impurity of $0.02 \%$.
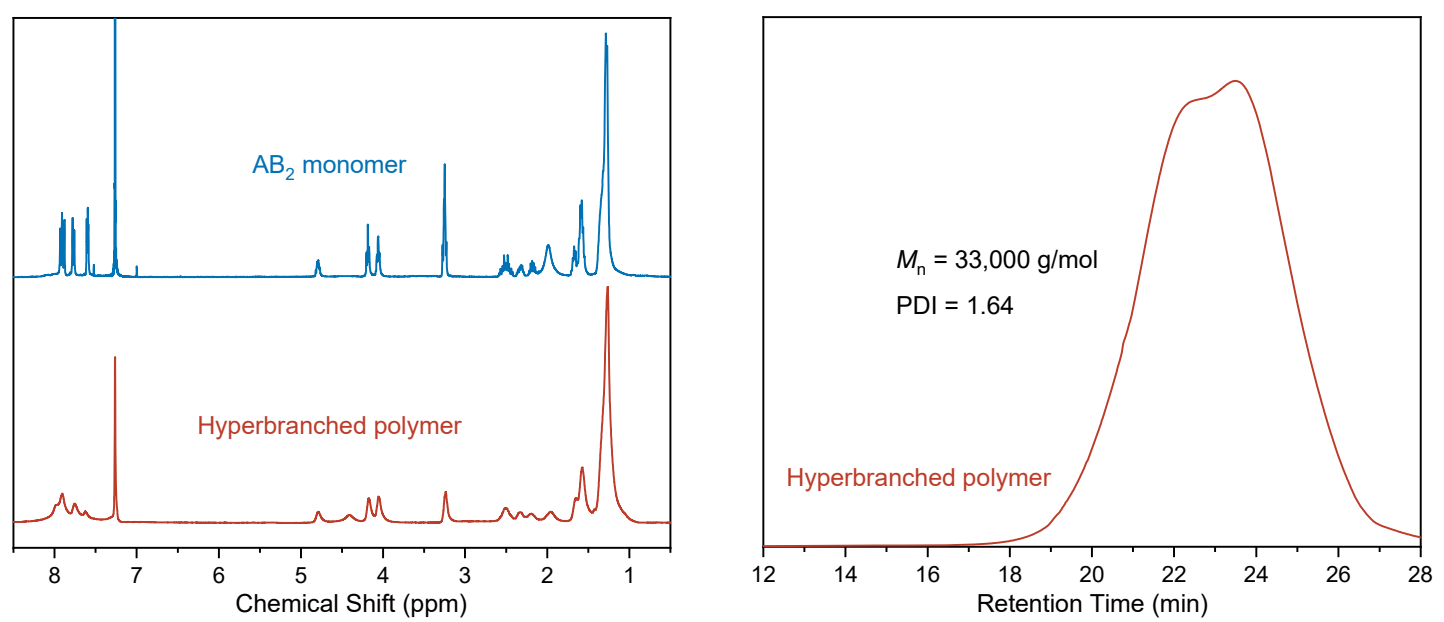

Figure S2. ${ }^{1} \mathrm{H}$ NMR spectra comparison of the $\mathrm{AB}_{2}$-monomer and thus obtained hyperbranched polymer (left), and the GPC trace of the hyperbranched polymer (right). 


\section{Thermal Analysis}

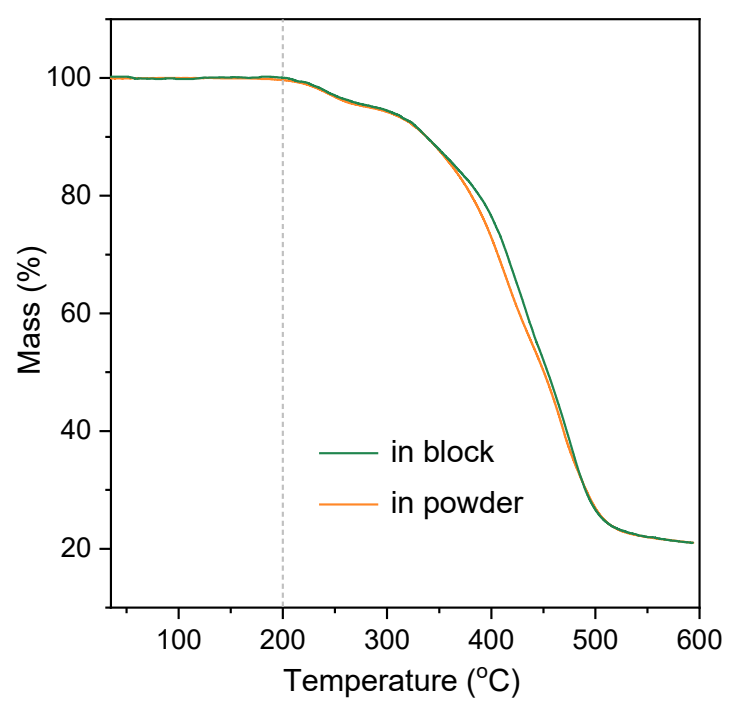

Figure S3. TGA curves of the HLCP collected at a heating rate of $20^{\circ} \mathrm{C} \mathrm{min}^{-1}$ from 35 to $600{ }^{\circ} \mathrm{C}$ under argon atmosphere.
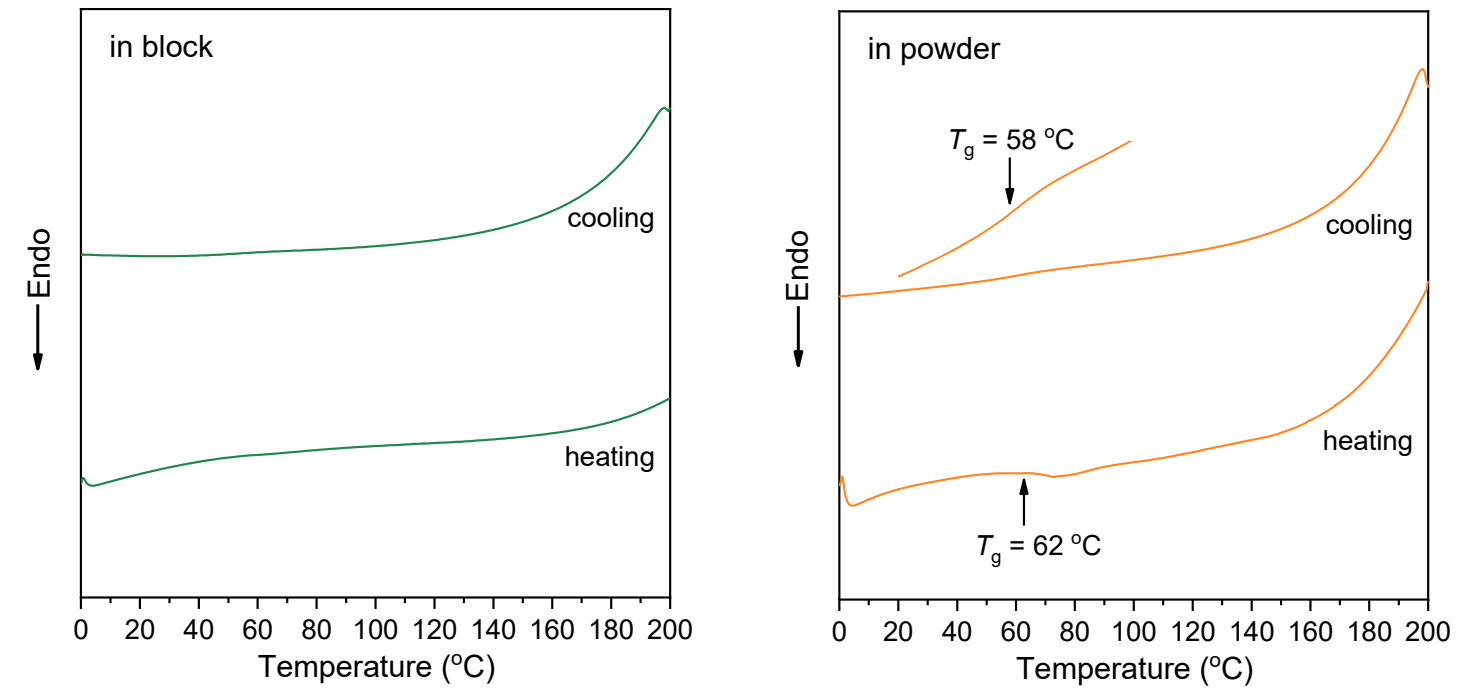

Figure S4. DSC traces of the HLCP in different states upon heating and cooling at a rate of $10^{\circ} \mathrm{C} \mathrm{min}^{-}$ ${ }^{1}$ under nitrogen atmosphere. 


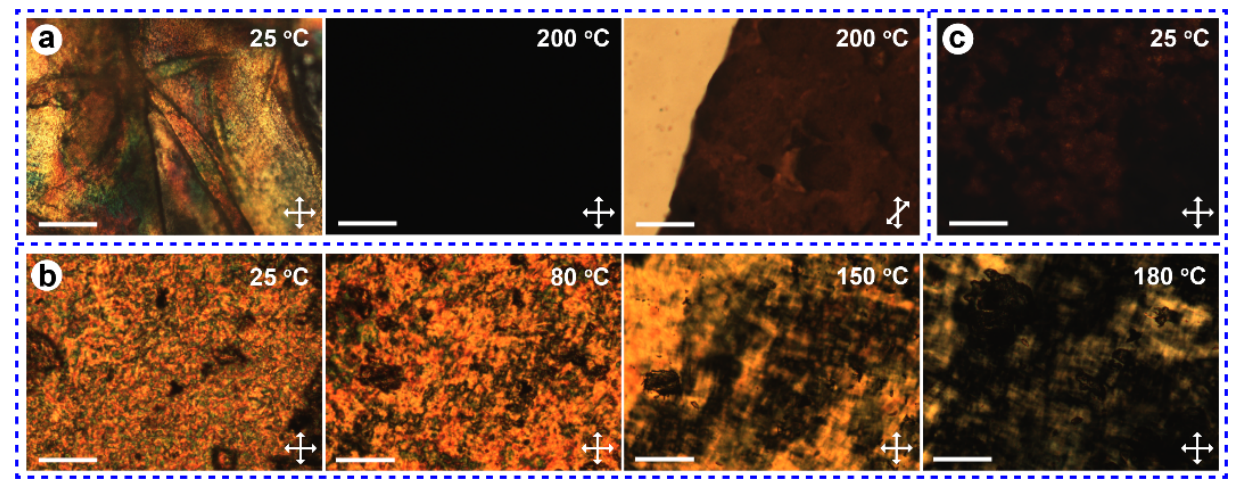

Figure S5. POM images of HLCP obtained from various processing methods including (a) as-prepared thin block, (b) thermally pressed powder, and (c) spin-coated film. Scale bar represents $400 \mu \mathrm{m}$.

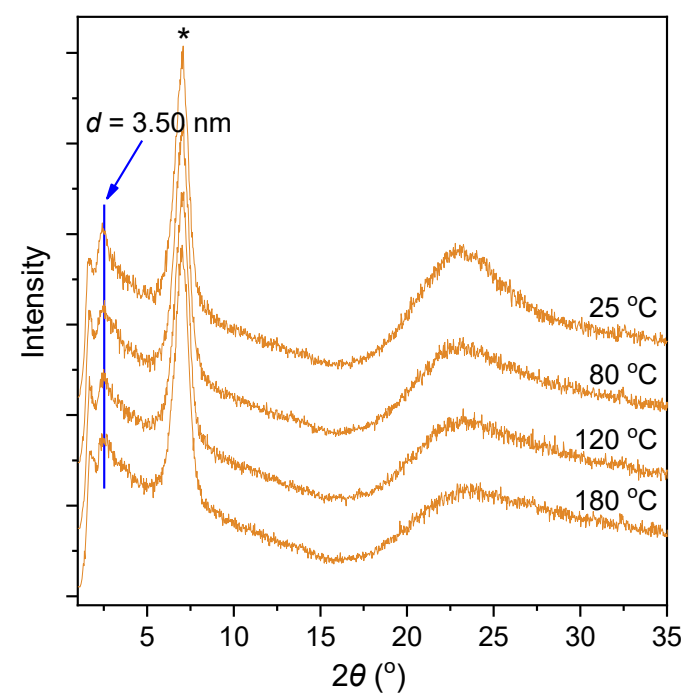

Figure S6. Variant temperature X-ray diffractograms of the HLCP, where the strong peak locating in the middle-angle region labeled by asterisk is corresponding to the background peak generated from the instrument.

As firstly examined by TGA (Figure S3), the obtained HLCP was thermally stable over $200{ }^{\circ} \mathrm{C}$. However, the DSC analysis (Figure S4) performed by cycling between 0 and $200{ }^{\circ} \mathrm{C}$ exhibited no phase transition peak, except for the powder solid with an obvious glassy transition around $60{ }^{\circ} \mathrm{C}$. In POM (Figure S5), though lack of typical LC textures, all the assembled HLCP solid showed obvious birefringence, indicating the formation of well-organized LC phases. In the case of solution evaporated block (Figure S5a), the birefringence can be retained until heating up to $200^{\circ} \mathrm{C}$, then extended domains gradually evolved which lacked birefringence and were surrounded by brown shades indicating decomposition of the textures as highlighted under $45^{\circ}$ crossed polarizers. As for the powder sample 
(Figure S5b), a different optical birefringence from that of thin block was observed, which gradually weakened during heating above the glassy temperature, accompanied with enhanced mobility of the sample, until direct thermal decomposition above $200{ }^{\circ} \mathrm{C}$. Variant temperature X-ray diffraction was then performed to examine the thermotropic behavior for the representative powder sample (Figure S6), which indicated that the HLCP exhibited LC phase that persisted with elevated temperature below $200{ }^{\circ} \mathrm{C}$. The peak at $d=3.50 \mathrm{~nm}$ was assigned to (002) diffraction of the lamellar smectic structure as discussed in Figure 3, while the broadened diffraction halo peak in the wide-angle region upon heating above the glassy temperature implied that the aliphatic segments became more disordered or mobile, agreeing well with the POM observation. The spin-coated film should have been in a lowly ordered metastable state, thus exhibited weak birefringence (Figure S5c). All these significant difference in thermal behaviors of the HLCP in varied forms of solid, provided additional evidence for their altered assembly mechanisms and molecular packing structures depending on the processing methods.

\section{Spectroscopic Properties}
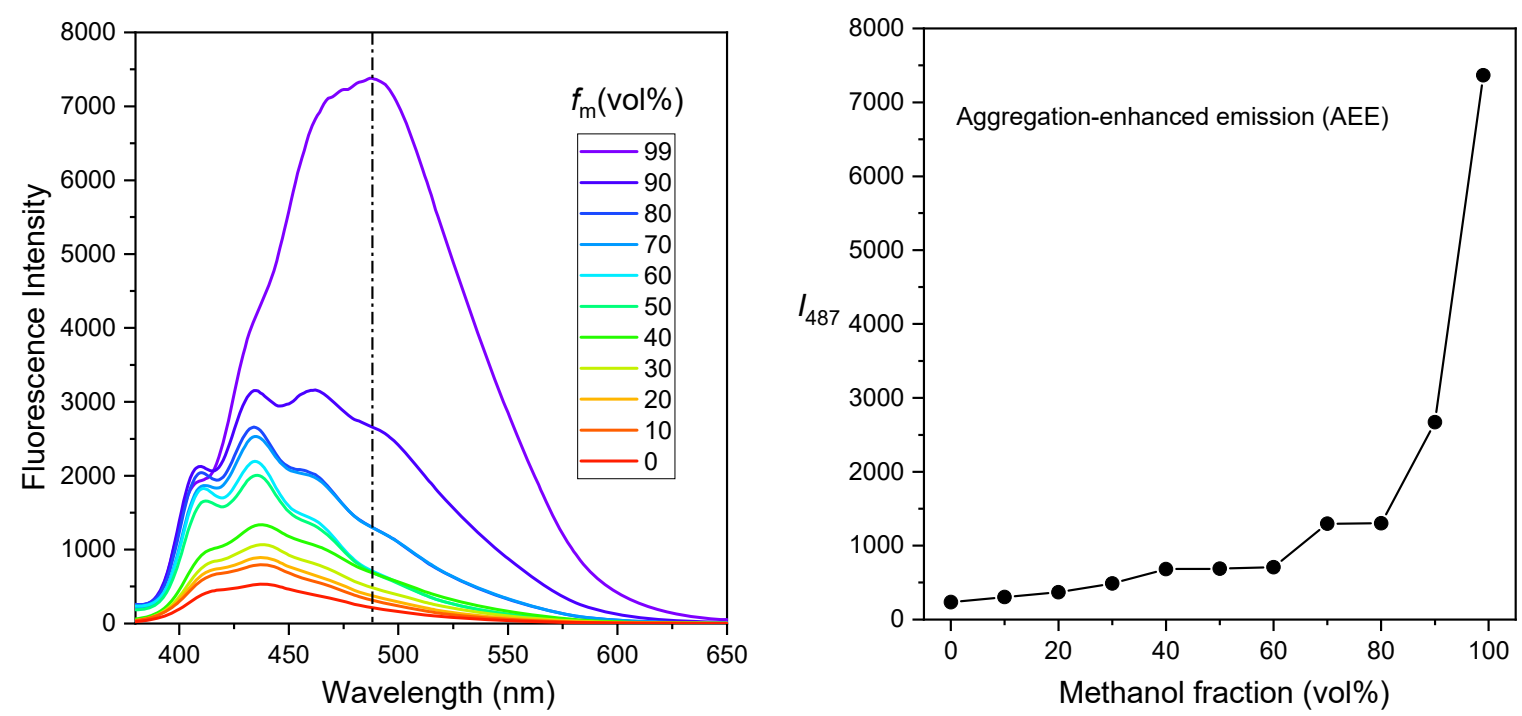

Figure S7. Fluorescence spectra of the HLCP in chloroform/methanol system with varied methanol fractions $\left(f_{\mathrm{m}}\right)$. And plot of the emission intensities at $487 \mathrm{~nm}\left(I_{487}\right)$ versus methanol fraction of chloroform $/$ methanol mixture of the HLCP. Concentration $=10^{-5} \mathrm{~mol} / \mathrm{L}$. Excitation wavelength $=350$ nm. 


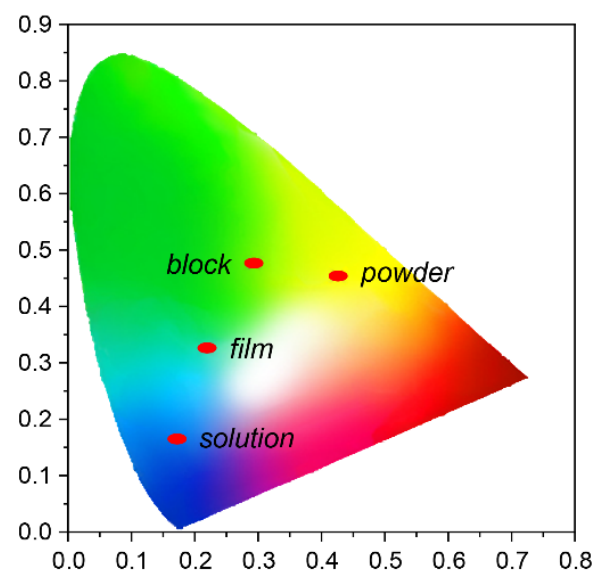

Figure S8. CIE chromaticity diagram showing the luminescent color change of the HLCP in different states.
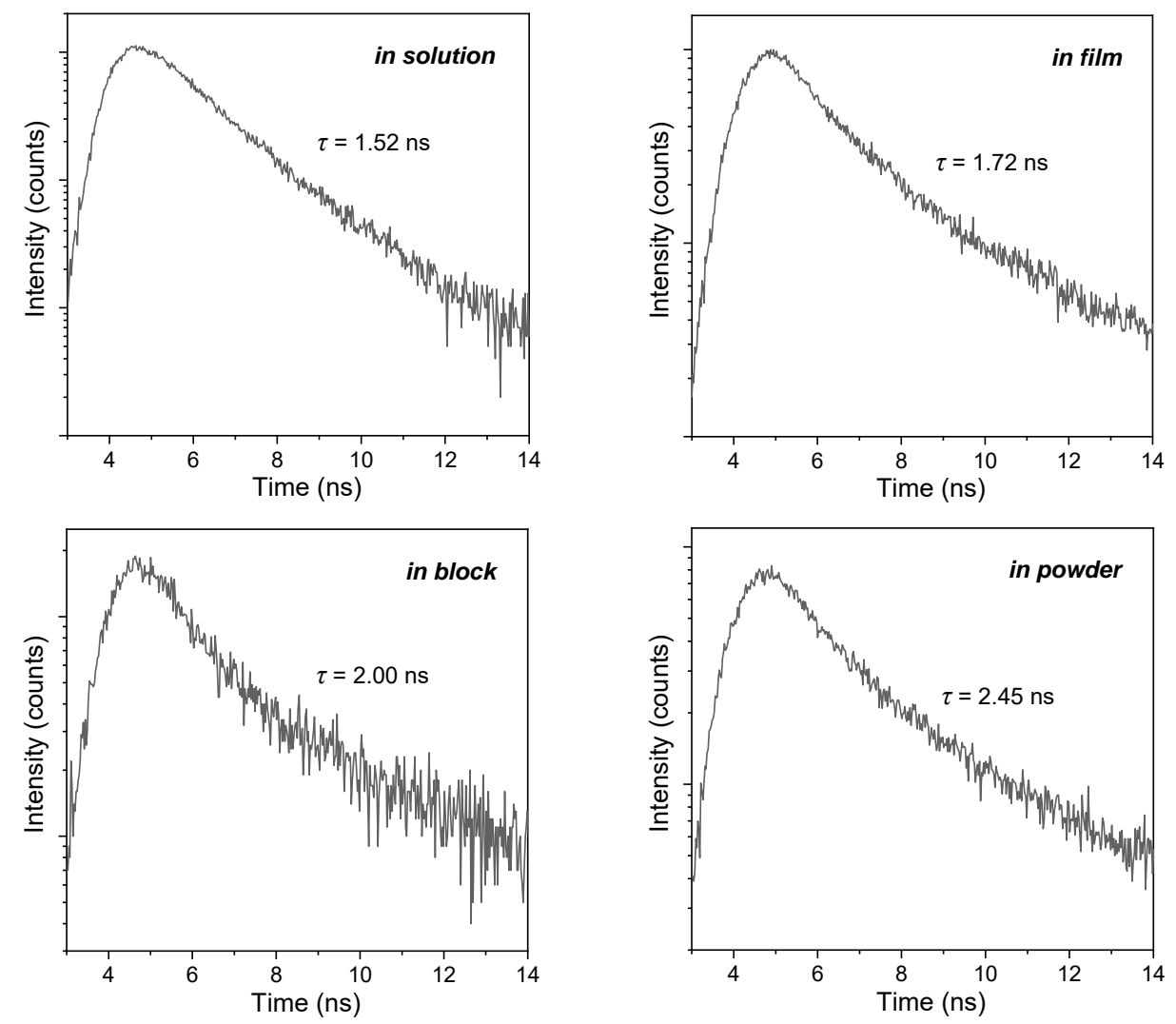

Figure S9. Time-resolved fluorescence decay profiles of the HLCP in different states. 


\section{Structural Characterization}

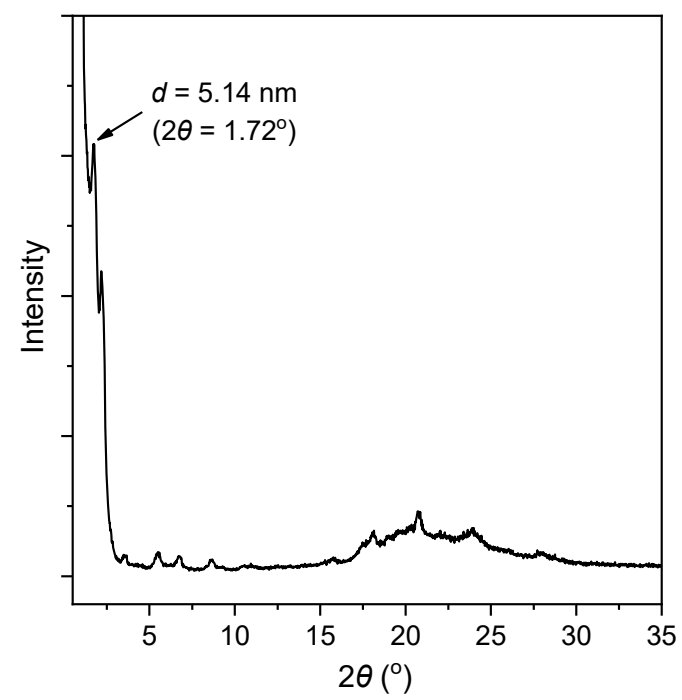

Figure S10. X-ray diffractogram of the crystalline $\mathrm{AB}_{2}$-monomer at room temperature.

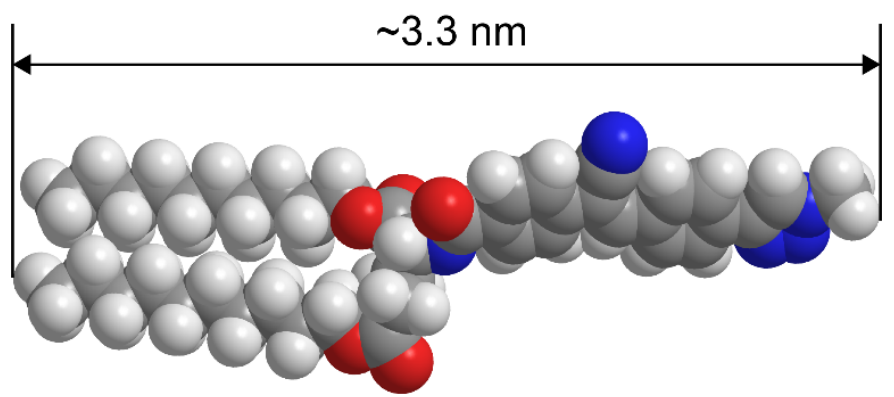

Figure S11. CPK molecular model showing the average length of the repeat unit of the HLCP around $3.3 \mathrm{~nm}$.

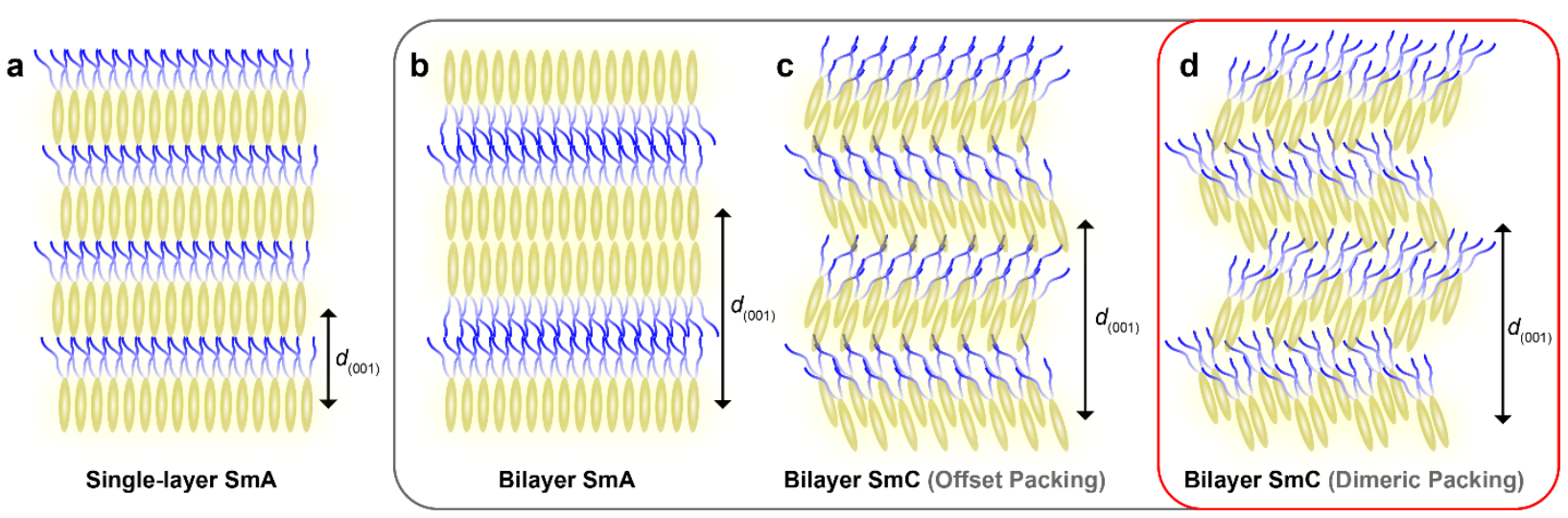

Figure S12. Possible packing structures for lamellar phase with the inter-lamellar spacing twice the length of the repeat unit. 
Phase Structure Analysis and Choice for the HLCP in Powder State: As deduced from the X-ray scattering, the spacing of the first reflection $(6.98 \mathrm{~nm})$ corresponding to twice the length of the repeat unit $(3.3 \mathrm{~nm})$, possibly suggests a bilayer orthogonal SmA phase. However, this main chain type LC polymer can only form the single-layer SmA phase (Figure S12a) and the bilayer SmA phase (Figure $\mathrm{S} 12 \mathrm{~b}$ ) is not possible to accommodate comfortably the alternating arrangement of CS mesogens and alkyl spacers. Therefore, the most probable structure is the bilayer tilted SmC phase (Figure S12c,d) similar to that in the block solid. Further based on the much more red-shifted UV-vis absorption and fluorescence emission spectra with respect to that in the block solid, a dimeric packing of the CS mesogens (Figure S12d) rather than the offset packing (Figure S12c) within each layer to satisfy the spectroscopic characteristic and larger inter-lamellar spacing should be the best choice.

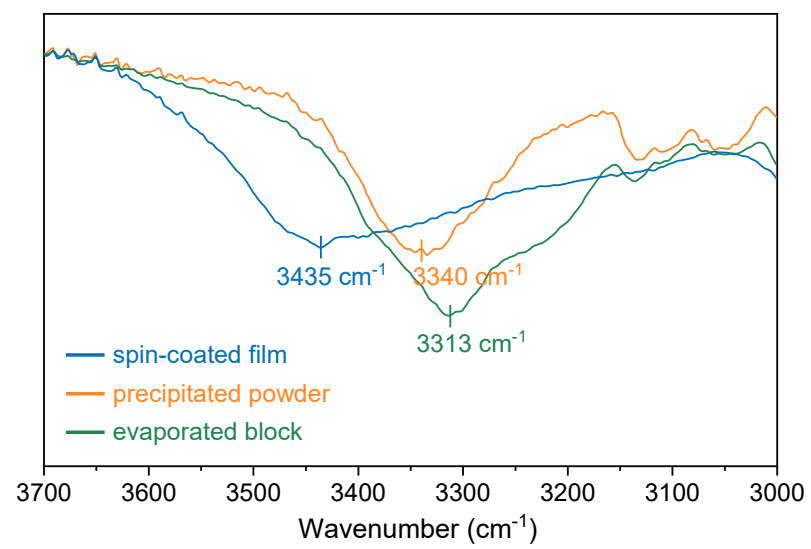

Figure S13. FTIR spectra collected from the HLCP in different situations, showing the difference in relevant amide $\mathrm{N}-\mathrm{H}$ vibrations between 3700 and $3000 \mathrm{~cm}^{-1}$. 


\section{Synthesis and Characterization of the Linear LC Polymer Analogue}
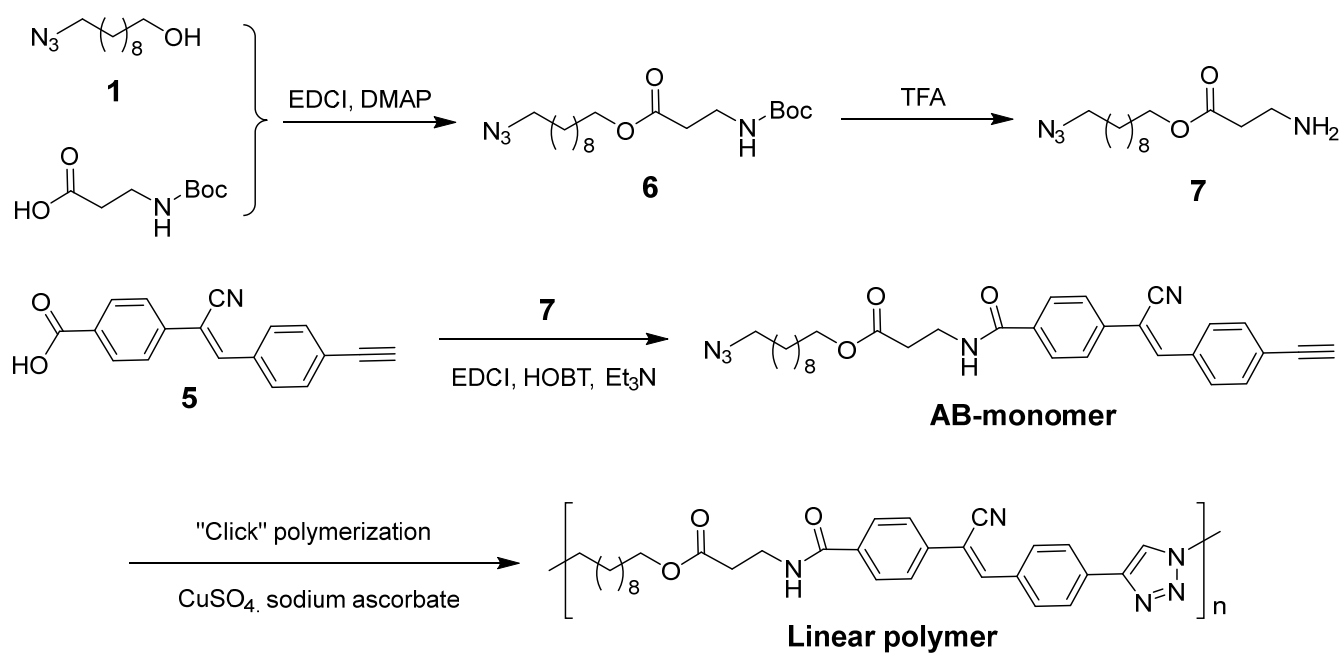

Scheme S3. Synthetic route of the linear polymer.

The synthesis of the linear polymer was conducted according to the same procedures in the preparation of the hyperbranched polymer, by adopting a linear AB-type $\beta$-alanine instead of the branched $\mathrm{AB}_{2}$-type glutamic acid.

10-azidodecyl 3-((tert-butoxycarbonyl)amino)propanoate (6). ${ }^{1} \mathrm{H} \mathrm{NMR}\left(400 \mathrm{MHz}, \mathrm{CDCl}_{3}\right): \delta(\mathrm{ppm})$ $=5.01(\mathrm{~s}, 1 \mathrm{H}), 4.10(\mathrm{t}, 2 \mathrm{H}, J=6.7 \mathrm{~Hz}), 3.40(\mathrm{t}, 2 \mathrm{H}, J=6.4 \mathrm{~Hz}), 3.27(\mathrm{t}, 2 \mathrm{H}, J=6.9 \mathrm{~Hz}), 2.53(\mathrm{t}, 2 \mathrm{H}$, $J=6.1 \mathrm{~Hz}), 1.69-1.54(\mathrm{~m}, 4 \mathrm{H}), 1.45(\mathrm{~s}, 9 \mathrm{H}), 1.41-1.23(\mathrm{~m}, 12 \mathrm{H})$.

10-azidodecyl 3-aminopropanoate (7). ${ }^{1} \mathrm{H} \mathrm{NMR}\left(400 \mathrm{MHz}, \mathrm{CDCl}_{3}\right): \delta(\mathrm{ppm})=4.10(\mathrm{t}, 2 \mathrm{H}, J=6.7$ $\mathrm{Hz}), 3.27(\mathrm{t}, 2 \mathrm{H}, J=6.9 \mathrm{~Hz}), 3.01(\mathrm{t}, 2 \mathrm{H}, J=6.2 \mathrm{~Hz}), 2.50(\mathrm{t}, 2 \mathrm{H}, J=6.2 \mathrm{~Hz}), 1.69-1.53(\mathrm{~m}, 4 \mathrm{H}), 1.42-$ $1.21(\mathrm{~m}, 12 \mathrm{H})$.

10-azidodecyl

(Z)-3-(4-(1-cyano-2-(4-ethynylphenyl)vinyl)benzamido)propanoate

(ABmonomer). M.P. $135{ }^{\circ} \mathrm{C} .{ }^{1} \mathrm{H}$ NMR $\left(400 \mathrm{MHz}, \mathrm{CDCl}_{3}\right): \delta(\mathrm{ppm})=7.90(\mathrm{~d}, 2 \mathrm{H}, J=8.4 \mathrm{~Hz}), 7.87(\mathrm{~d}$, $2 \mathrm{H}, J=8.6 \mathrm{~Hz}), 7.76(\mathrm{~d}, 2 \mathrm{H}, J=8.4 \mathrm{~Hz}), 7.61(\mathrm{~d}, 2 \mathrm{H}, J=8.8 \mathrm{~Hz}), 7.60(\mathrm{~s}, 1 \mathrm{H}), 6.97(\mathrm{t}, 1 \mathrm{H}, J=5.7$ Hz), $4.14(\mathrm{t}, 2 \mathrm{H}, J=6.7 \mathrm{~Hz}), 3.77(\mathrm{~m}, 2 \mathrm{H}), 3.27(\mathrm{t}, 2 \mathrm{H}, J=7.1 \mathrm{~Hz}), 3.27(\mathrm{~s}, 1 \mathrm{H}), 2.69(\mathrm{t}, 2 \mathrm{H}, J=5.8$ $\mathrm{Hz}), 1.76-1.54$ (m, 4H), 1.42-1.19 (m, 12H). ${ }^{13} \mathrm{C}$ NMR (100 MHz, DMSO-d6): $\delta(\mathrm{ppm})=171.86$, $165.73,143.39,136.50,135.23,134.32,132.72,129.94,128.48,126.20,124.41,117.96,110.77,83.92$, $83.52,64.42,51.04,36.16,34.21,29.37,29.31,29.16,29.01,28.69,28.60,26.61,25.90$. ESI-MS $(\mathrm{m} / z)$ : 
$[\mathrm{M}+\mathrm{Na}]^{+}$calcd 548.26, found 548.16.

Linear polymer. The linear polymer was synthesized in a similar azide-alkyne click polymerization, but was carried out in a $\mathrm{CuBr}-N, N, N^{\prime}, N^{\prime \prime}, N^{\prime \prime}$-pentamethyldiethylenetriamine (PMDETA) system. However, the obtained linear polymer cannot be dissolved in some common organic solvents such as tetrahydrofuran (THF), N,N-dimethylformamide (DMF), chloroform, and 1,3,5-trichlorobenzene that were usually used as eluents in the GPC analysis, which make it difficult to determine the relative molecular weight. Like the traditional polyamide materials, this linear polymer shows relatively good solubility in formic acid, due to the significance of formic acid in breaking the inter-/intra-chain hydrogen bonds, thus it is feasible to process this linear polymer in different situations as we did in the hyperbranched polymer system.

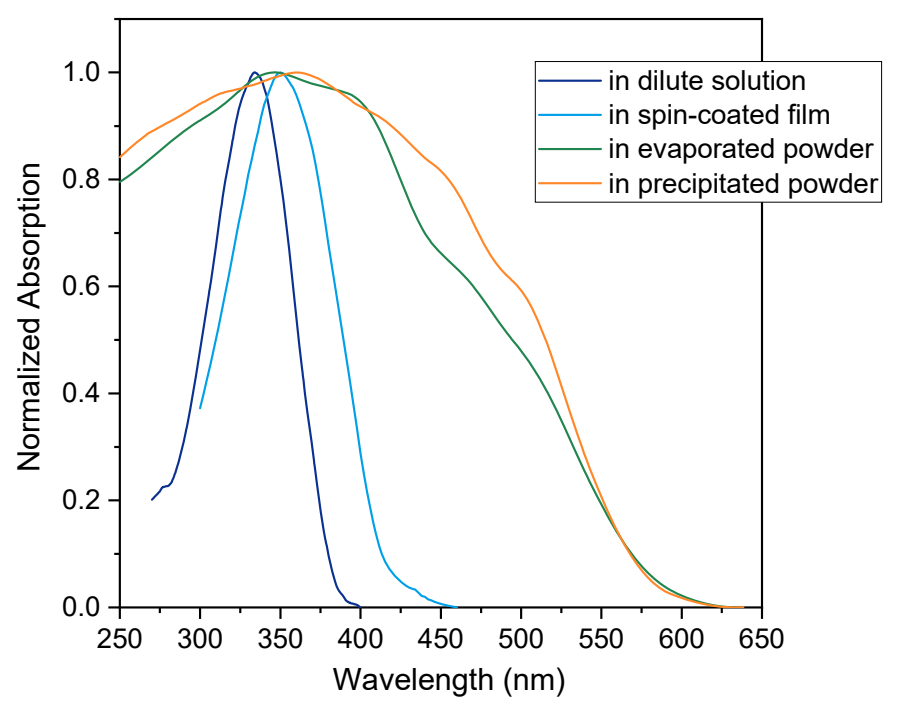

Figure S14. Normalized UV-vis absorption spectra of linear LC polymer analogue collected from its formic acid solution and solid state formed by various processing methods. 

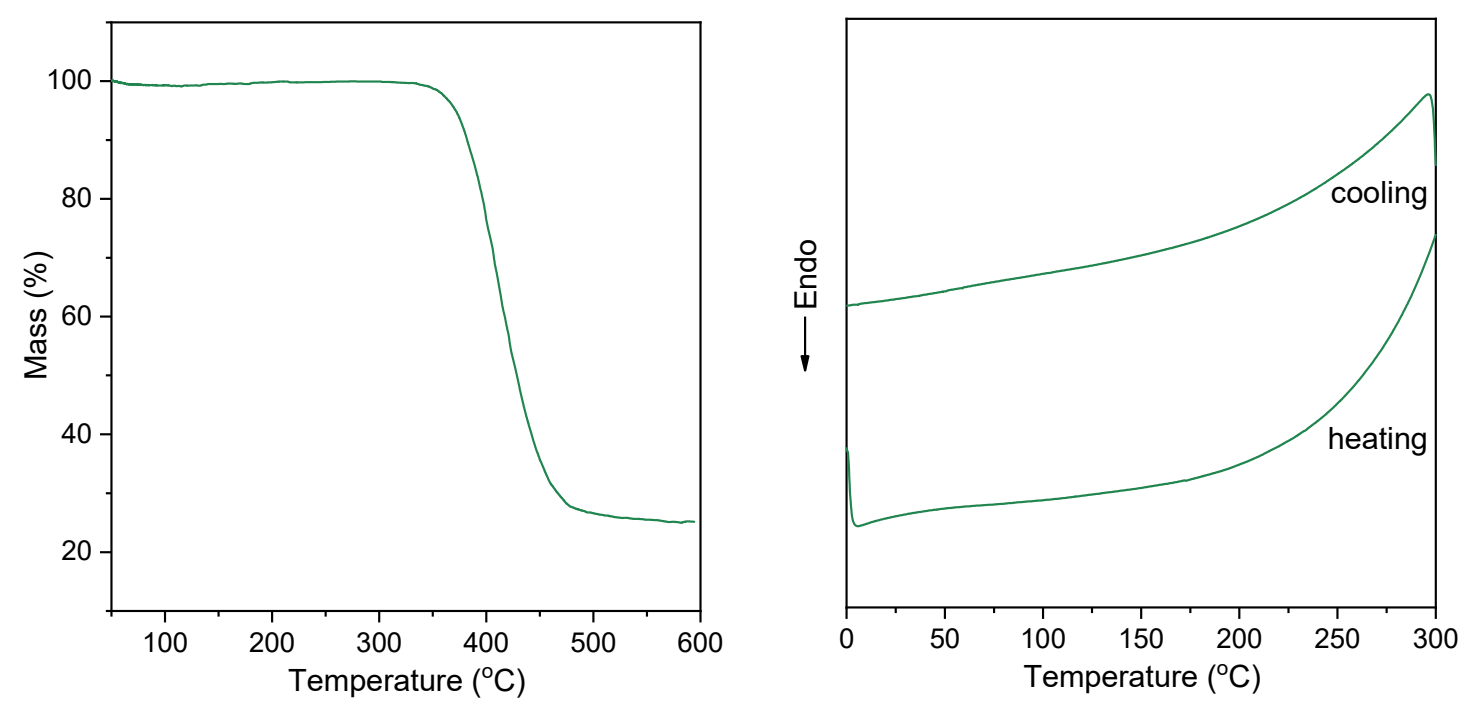

Figure S15. TGA curve of the linear LC polymer analogue collected at a heating rate of $20^{\circ} \mathrm{C} \mathrm{min}^{-1}$ under argon atmosphere, and DSC traces upon heating and cooling at a rate of $10{ }^{\circ} \mathrm{C} \mathrm{min}^{-1}$ under nitrogen atmosphere.
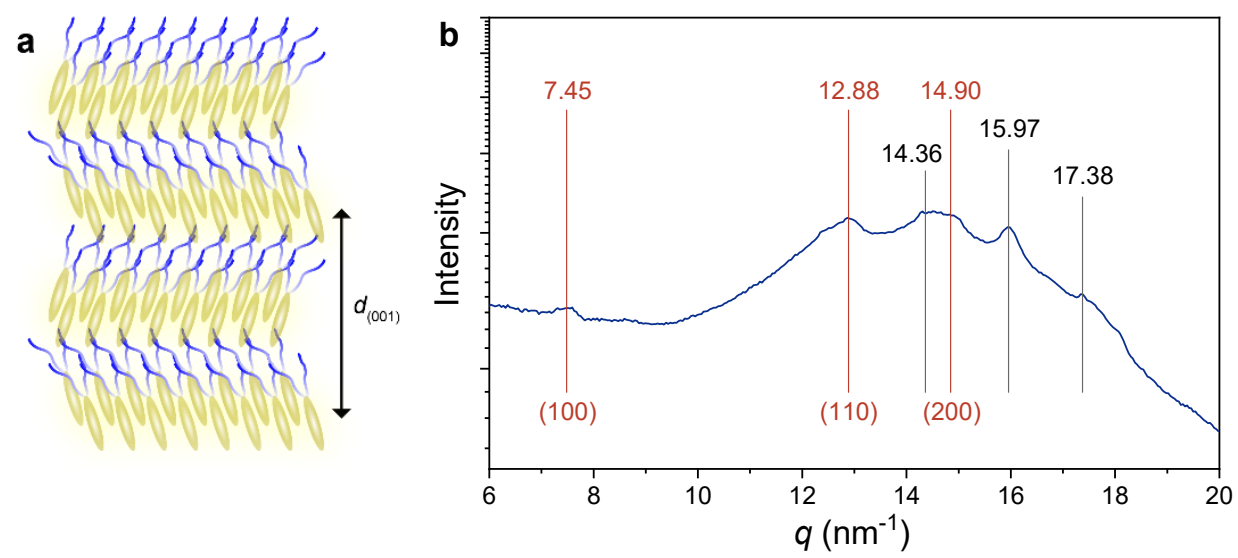

Figure S16. (a) Proposed packing structures for bilayer lamellar phase, and (b) X-ray scattering in the wide-angle region of the linear LC polymer analogue indicated with proposed indexing.

Smectic Phase Assignment for the Linear LC Polymer Analogue: X-ray scattering in the smallangle region has demonstrated the bilayer tilted smectic structure (Figure S16a), while the wide-angle scattering (Figure S16b) can provide critical information about the packing states of mesogens. The three scattering peaks indicated by red line with $q$-ratio of $1: \sqrt{ } 3: 2$ can be assigned to a $\mathrm{SmF}$ or $\mathrm{SmG}$ phase where the mesogens are hexagonally packed with the reciprocal distance calculated as $0.97 \mathrm{~nm}$ from the (100), (110) and (200) scattering. However, the remaining three scattering peaks indicated by gray line may be indicative of a long-range periodic ordering within the layers and between the layers, 
thus the most probable structure can be identified as SmG phase.
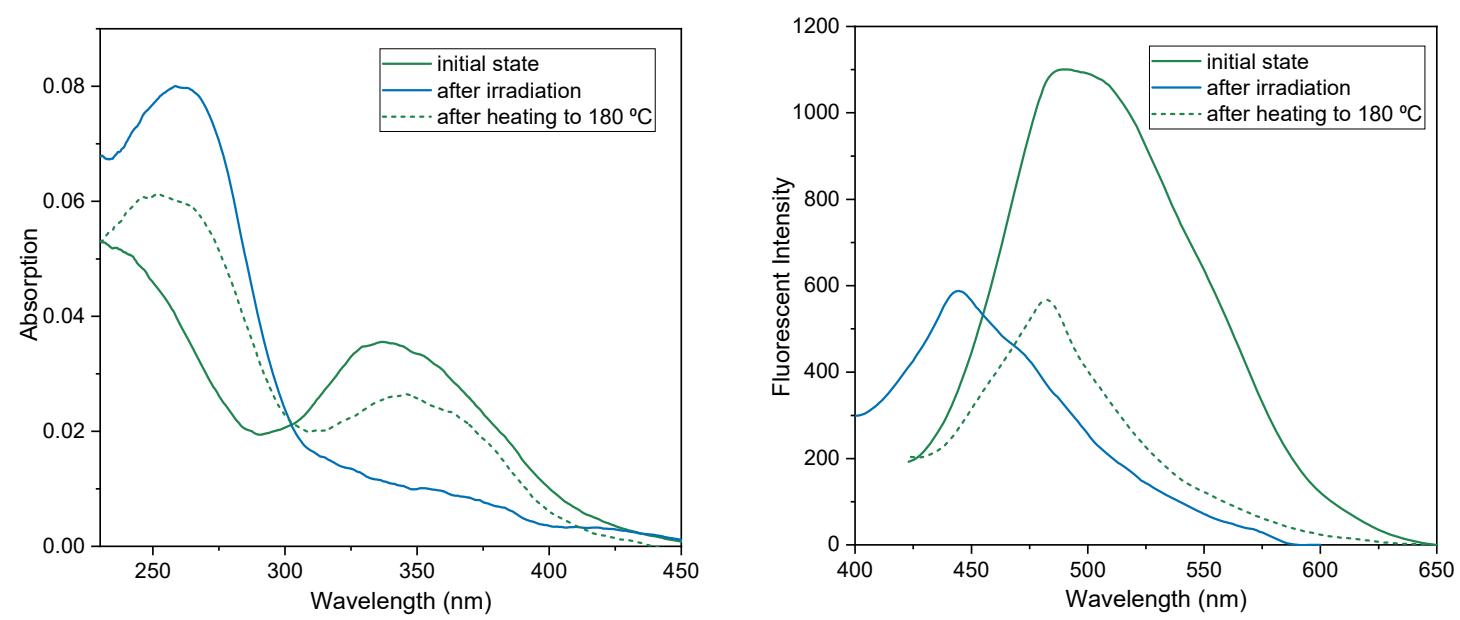

Figure S17. UV-vis absorption and fluorescent emission spectra of the linear LC polymer film before (green solid line) and after (blue solid line) $365 \mathrm{~nm} \mathrm{UV}$ irradiation and subsequent thermal treatment at $180{ }^{\circ} \mathrm{C}$ (green dashed line).

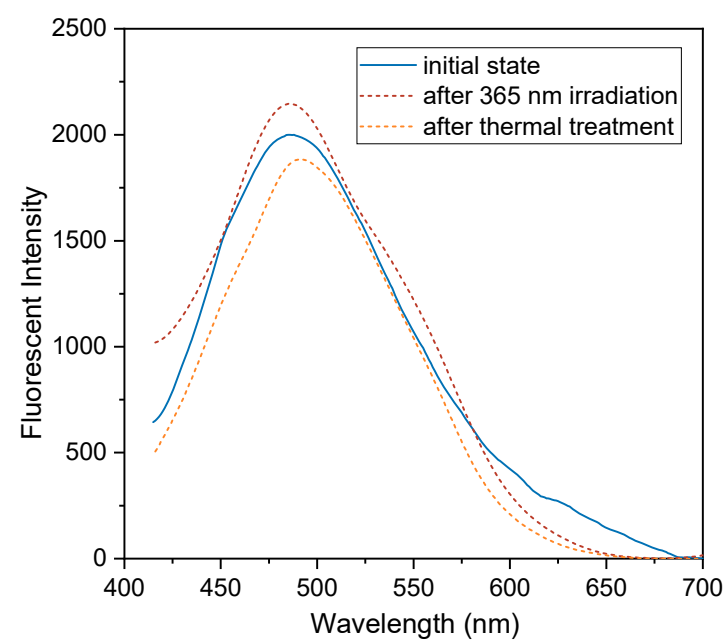

Figure S18. Fluorescent emission spectra of the spin-coated HLCP film (blue solid line), and after 365 nm UV irradiation (red dashed line), or after thermal treatment (yellow dashed line). 